\title{
Poverty, Food Security and Women Employment in Urban Ethiopia (A Case Study in Sodo Town)
}

\author{
Nega Mathewos \\ College of Business and economics, Wolaita Sodo University, Wolaita, Ethiopia
}

\begin{abstract}
Ethiopia is one of the world's poorest countries in the world. The country suffers spells of drought, which resulting famines and such conditions have a strong influence on the living standards of the whole population, particularly in the north and the dry southeast part of the country. Data from a survey of 100 inhabitants of Sodo town were used to examine the extent and determinants of poverty in the town, and the systematic relationship between women's income and household expenditure pattern. Both descriptive and econometrics analysis were used. Logit Model the study was used to analyze and identify the determinants of poverty in the town. The econometric variables educational level, occupation and age of the household head and family size were found to be the significant parameters in determining the probability of being under poverty. On the top of that, by applying a simple microeconomics concept, Engel curve, the study attempted to analyze the effect of percentage share of female's income in a household on the expenditure pattern of the household on different food items. The result attested that percentage share of female's income in a family has a positive and significant effect on vegetables and fruits, and spices expenditures. Educational status of the head was appeared a significant factor in determining the probability of being poor. Meaning, those households whose head has attended more schooling is less likely to be in absolute poverty. Age of the household head also has a negative and significant effect on the probability of being poor. This is to mean that as age of the hhh increases the probability of being under poverty go down. As it was evident from the head count poverty index, nearly half of the surveyed households were under poverty i.e. they were unable to meet the minimum expenditure on food items for survival. From this result, therefore, the study suggests that urban poverty should be get due emphasis from the concerned body. Creating a good employment opportunities for women has a paramount of significance not only in the alleviation of poverty and achievement of food security but also for realization of nutrition security. Since most of the households which are headed by old age persons are under absolute poverty, there should be a good social security system as far as what is possible.
\end{abstract}

DOI: $10.7176 / \mathrm{JCSD} / 52-01$

Publication date:October $31^{\text {st }} 2019$

\section{INTRODUCTION}

\subsection{Background of the Study}

Ethiopia is one of the world's poorest countries by any standard. According to a recent World Development Report, the country has the lowest GNP per head in the world, and its purchasing power parity adjusted GNP is ranked $200^{\text {th }}$ out of 206 countries (World Bank 2000). Human development indicators of the United Nations Development Program (UNDP) also attest to the seriousness and extent of poverty in the country. For instance, the Human Development Index (HDI) of Ethiopia is the eighth lowest out of 177 countries in the world. Similarly, the Human Poverty Index (HPI) ranks Ethiopia $92^{\text {nd }}$ out of 95 developing countries where the $95^{\text {th }}$ is the poorest of all (UNDP, 2004).

The country suffers spells of drought, which resulting famines and such conditions have a strong influence on the living standards of the whole population, particularly in the north and the dry southeast part of the country. Another major growth deterrent for many years in the country had been internal conflicts, including the recent war with Eritrea. These major shocks have important implications for the welfare of both urban and rural households. In urban areas, the impact of the shocks is felt mainly through higher food prices and increased rural- urban migration, often contributing to increased urban poverty (Abbi Mamo Kedir, 2003).

The poverty experienced by many Ethiopians is reflected in a range of well-being measures of the population. For example, the life expectancy at birth in the country is approximately 46 years, which is substantially lower than the average 77 and 67 years recorded for countries with high and medium human development indices, respectively. Moreover, three quarters of the population do not have access to an adequate water source, a figure that is amongst the highest for countries experiencing a low measure of human development. The percentage of population with access to suitable sanitation, which stands at 12 per cent, is significantly lower than the 53 per cent average for the sub-Saharan Africa. On the other hand, the adult illiteracy rate at around 60 percent is significantly higher than the average for sub-Saharan Africa and other developing countries. (Tesfaye, 2006)

This paper contributes to the literature examining poverty in Ethiopia. In particular, updated estimates are provided of the nature and extent of poverty experienced by Ethiopians residing in Sodo city. Further, the determinants of poverty are sorted out by using the appropriate econometric model. Moreover, the association 
between women and poverty is concerned. This will have a direct bearing on policymaking, as it will aid in prioritizing women and different types of households in the effort to tailor resources to the needy.

\subsection{Statement of the Problem}

Despite significant improvements over the past half century, extreme poverty remains widespread in the developing world. More than 1.2 billion people live on less than $\$ 1$ per day and more than 2.8 billion(almost half of the world's population) live on less than $\$ 2$ a day (Todaro, 2003). This worldwide chronic poverty is extensively manifested in our country in general and in urban centers in particular.

In Ethiopia poverty is the general feature for the nation and causing many sufferings and anguish to the largest proportion of the population. It is high agenda of the government, donor agencies, NGOs and other actors. The government has been formulating and implementing various policy interventions and programs that are in one way or another related to poverty reduction.

Currently, though poverty is taken as the country's rural phenomena there is a diffusion and growth of urban poverty. Indeed, the number of urban poor is increasing at unprecedented rate. This is due in part to the highest rural-urban exodus and alarming internal population growth (Dessalegn and Aklilu, 2002). In effect, the urban economy has limited capacity to accommodate the populous. In such a situation, employment in the formal sector is tough and the probability of getting commendable job opportunities, in fact, could be daunting.

The impoverished people who live in urban centers of Ethiopia often suffers from under nutrition and health problem, have little or no literacy, have little political voice, live in environmentally degraded areas and attempts to earn a meager living on dilapidated urban slums.

Women constitute a substantial majority of urban centers poor. Across Ethiopia, women and children experience the harshest deprivation. They are malnourished, receive less medical services, clean water and sanitation, lower earning capacity, less access to education, formal sector employment, social security and government employment programs. Because of these factors financial resources of poor women are meager and unstable relative to men's.

Women are often paid less for performing similar task. In urban areas, women are much less likely to obtain formal employment in private companies or public agencies and are generally limited to low productivity jobs.

Having the above afro mentioned points in mind, the researcher is eager to conduct a study on this title i.e. what is the feature of poverty and food security in Sodo town and what would happen to the existing situation if women in urban areas in general and in the city in particular were drawn into economic mainstream?

\subsection{Objectives the Study}

\subsubsection{General objective}

The overall objective of the study was assessing the existing poverty, food security and women employment in Sodo town.

\subsubsection{Specific objectives}

The specific objectives of the study were

$>$ To examine the extent of poverty in the city

$>$ To identify the different parameters that determines poverty in city

$>$ To examine the existence of systematic relationship between household expenditure patterns and women income

\section{RESEARCH METHODOLOGY}

\subsection{Nature and Source of Data}

Proportional samples were taken from all kebels in each of the town and half of the kebeles (the lowest administration units) selected randomly from each town. Finally, using the registration of residential houses at the kebele administrative offices as the sampling frame, systematic sampling was used to select households from each of the kebeles. Using such a frame captures households living in own residences, government and kebele houses and tenants in registered private housing. Such an approach, however, fails to capture homeless individuals and family units. If poverty is particularly pronounced among the homeless, as one might expect a prior, the level of poverty measured may be underestimated.

In the survey, information was collected on a multitude of socioeconomic variables of interest including the structure and composition of the household, educational and health status, employment and income, consumption and expenditure, and credit.

\subsection{Method of Data Analysis}

To meet the objectives of the study the analysis should be undertaken with a great care. To this end, the researcher was employed different data analysis methods consisting of both descriptive (includes: percentage, averages, indexes, etc.) and econometrics tools. 


\subsubsection{Model specification}

As it is mentioned earlier, the study tries to apply econometrics tools in order to analyze

$>$ The determinants of urban poverty

$>$ The relationship that exist between expenditures on different food items and other interest of variables

A) Model 1 (especially with percentage share of women's income in a household.)

In order to analyze the correlates of urban poverty a Logistic regression model was employed with the dependent variable being the dichotomous of whether the household is poor (1) or not poor (0). The explanatory variables considered in the analysis are demographic characteristics (sex, age, and family size), marital status, educational level, occupation, religion and location.

\section{Construction of poverty line}

To begin with, the econometric analysis, first defining the poverty line for the period, which the survey was conducted, is mandatory. The households are classified as poor and non-poor by using the poverty line as a cutoff point.

To do so, in this study a poverty line estimate previously determined for urban Ethiopia by Tadesse (1999) which was 88 birr per month per adult equivalent is used. The food poverty line that underline this estimate was defined using the cost of basic needs approach. He constructed a food basket consisting of the average quantities of food consumed by a standard consumer to acquire 2200 calorie of energy per adult per day to determine the poverty line. The bundle of urban household consumption items value at market price to obtain food poverty line. In this analysis hence, if a household average consumption is below 88 birr per month the household is classified as poor and if not below 88 birr, not poor.

\section{The Logit Model}

Logit model is appropriate when we assume the random components of response variables follow binomial distribution and when most variables have categorical responses. Put differently, it is suited when the dependent variable is dichotomous and of the type that have a yes or no response. The form of the Logit model following Gujarati (2006) is:

$$
Y=\alpha+\beta_{1} X_{1}+\beta_{2} X_{2}+\beta_{3} X_{3}+\ldots .+\beta_{k} X_{k}+\varepsilon
$$

$$
\beta_{i} X_{1} \text { runfrom } \beta_{1} X_{1 t} \text { to } \beta_{k} X_{K}
$$

Where,

Ý $=$ Probability of a household being poor or non-poor

$\alpha=$ Intercept (constant) term

$\beta_{k}=$ Coefficients of the predictors estimated using the maximum likelihood method

$\mathrm{X}_{\mathrm{i}}=$ Predictors (independent variables)

$\varepsilon=$ Random effect (error term)

Aggregating the value yields

$$
\underline{\mathrm{Y}=} \alpha+\sum_{k=1}^{k} \beta_{k} X_{k}+\varepsilon
$$

In practice $\mathrm{Y}$ is unobserved, and $\mathcal{E}$ is symmetrically distributed with zero mean and has cumulative distribution function $(\mathrm{CDF})$ defined as $\mathrm{F}(\varepsilon)$. What we observe is a dummy variable y, a realization of a binomial process defined by

$$
\mathrm{y}=\left\{\begin{array}{l}
\text { 1ify }>o \\
\text { 0othewise }
\end{array}\right\}
$$

From equation (2) leaving the constant term and rewriting the model yields

$$
=\text { Prob }\left(\varepsilon>-\sum_{k=1}^{k} \beta_{k} X_{k}\right)
$$




$$
=1-F\left(-\sum_{k=1}^{k} \beta_{k} X_{k}\right)
$$

The Logit model usually takes two forms. It may be expressed in terms of Logit or in terms of event probability. When expressed in Logit form, the model is specified as

$\log _{\log }\left[\frac{P(y=1)}{1-P(y=1)}\right]=\sum_{K=1}^{K} \beta_{K} X_{K}$

Using equation 4 and 5 can be transformed into a specification of the Logit model of event probability by replacing the general CDF, F, with a specific CDF, L representing the Logistic distribution

$$
\operatorname{Pr} o b(y=1)=1-L\left[\sum_{k=1}^{k} \beta_{k} X_{k}\right]=L\left[\sum_{k=1}^{k} \beta_{k} X_{k}\right]=\frac{e^{\sum_{k=1}^{k} \beta_{k} X_{k}}}{1+e^{\sum_{k=1}^{k} \beta_{k} X_{K}}}
$$

The above equation represents the probability of an event occurring. For a non-event, the probability is just 1 minus the event probability.

$$
\operatorname{Pr} o b(y=0)=\left[-\sum_{k=1}^{k} \beta_{k} X_{k}\right]=L\left[\sum_{k=1}^{k} \beta_{k} X_{k}\right]=\frac{e^{-\sum_{k=1}^{k} \beta_{k} X_{k}}}{1+e^{-\sum_{k=1}^{k} \beta_{k} X_{k}}}
$$

On the light of the above explanation, we can develop our urban poverty model as follows

$$
\mathrm{UP}=f(\mathrm{AGE}, \mathrm{AGE} \text { SQUARE, SEX, EDUST, MS, OCC, FS, DLC, U) }
$$

The list of variables with their definition is given below

EDUST $=$ Educational status of the house hold head

As the variable education is qualitative (ordinal) in nature, it is necessary to consider the mutually exclusive levels of education separately. Accordingly, the household head can be classified as not attended formal education, primary, secondary, and college and above. Since incorporating all educational level in terms of dummies in to our model results in multicollinearity, we have to omit one of them: for our case, we omit those who are not attended formal education.

EDUST $_{1}=1$, if the hhh has attended primary school.

$$
=0 \text {, otherwise. }
$$

EDUST $_{2}=1$, if the hhh has attended secondary school.

$$
=0 \text {, otherwise. }
$$

EDUST $_{3}=1$, if the hhh has attended college and above

$$
=0 \text {, otherwise. }
$$

$\mathrm{AGE}=$ Age of the hhh, in year

AGE SQUARE $=$ Square of the age of the hhh

$\mathrm{SEX}=$ Sex of the hhh

$\mathrm{Sex}=1$, if the hhh is female

$=0$, otherwise

MS= Marital status of the respondent

$\mathrm{Ms}=1$, if the respondent have married.

$=0$, otherwise

$\mathrm{OCC}=$ Occupation of the hhh

$\mathrm{Occ}_{1}=1$, if the $\mathrm{hhh}$ is self-employed

$$
=0 \text {, otherwise }
$$

$\mathrm{Occ}_{2}=1$, if the hhh is wage earner $=0$, otherwise.

$\mathrm{Occ}_{3}=1$, if the hhh is casual worker $=0$, otherwise

$\mathrm{Occ}_{4}=1$, if the $\mathrm{hhh}$ is pensioner $=0$, otherwise

$\mathrm{Occ}_{5}=1$, if the hhh is unemployed 


$$
=0 \text {, otherwise }
$$

$\mathrm{FS}=$ Family size in numbers

$\mathrm{DLC}=$ Duration of living in the city

$\mathrm{Dlc}=1$, if the house hold live less than 10 years

$=0$, otherwise

$\mathrm{U}=$ Stochastic term, showing the impact of all other factors not included in the model.

\section{Description of Explanatory Variables}

\section{Educational status of the household head}

This variable was generally expected to have a negative sign. This was because, under normal circumstances a more educated hhh has a better employment opportunity and a good access (know how) in income generating activities. Further, it is known that whenever one achieved a higher and higher educational level the earning power of the individual will be increased.

\section{Age of the household head}

Once experience is expected to increase with time and he/she will be equipped with how to manage his /her family. In addition to this, it is expected that as age goes up, the assets of a household is assumed to be increased. However, in some cases, as people gets older they are unable to perform what is expected from them. As a result, there might be a decline in income.

\section{Sex of the household head}

Since women in LDCs have not a better access to economic activities, a female-headed household is expected to be more vulnerable to poverty.

\section{Marital status of the household head}

It is presumed that being married is well for higher income. Meaning there is a probability of different income sources.

\section{Occupation of the household head}

In reality, it is explicitly known that wage earner and those who have their own business are not that much expose to poverty. In the contrary, disables, casual workers and unemployed people are usually highly vulnerable to poverty.

\section{Family size of the household}

Those households, which have large family size, are supposed to have higher probability of being under poverty.

7. Duration of living in the city:

It is expected that households living more than 10 years in the city are less vulnerable to poverty than new comers.

B) Model 2

In order to analyze the relationship between household consumption pattern and women's income we use the simple microeconomic concept i.e. Engel curve. The analysis begins with a standard Engel curve relationship between expenditure on specific groups of goods and household income, introduced by Working (1934). This is a linear relationship between the share of expenditure on each good and the natural logarithm of total expenditure. Household demographics and other characteristics are also included, following Deaton (1997). The components of household consumption expenditure are divided into food cereals and pulses, spices, vegetable and fruits, and drinks \& stimulants, to determine whether there happens a systematic relationship between the percentage share of women's income in the family and the respective expenditures.

The functional form of the basic household level regression is

$\mathbf{W}_{\mathbf{i}}=\beta_{\mathbf{0}}+\beta_{1}(\mathbf{Y} / \mathbf{n})+\beta_{2}(\mathbf{n})+\beta_{4} \ln (\mathbf{p s w i})+\beta_{3}$ edust $+u_{i}$

Where $\mathbf{W}_{\mathbf{i}}$ is the share of the budget devoted to good(food item) $\mathrm{i}$, and the five categories of food items considered in this preliminary study are food cereals \& pulses, spices, vegetable and fruits, milk \& meat, and drinks \& stimulants for home consumption (that is, excluding meals bought outside the home). $\mathbf{Y}$ is total household income; $\mathbf{n}$ is the size of the household; edust is the educational level of the household head (ordinal variable tacking 1,2 , 3 , and 4 for illiterate, primary, secondary and college respectively); pswi is the percentage share of women's income in the household and $\mathbf{u}_{\mathbf{i}}$ is stochastic term, showing the impact of all other factors not included in the model. Note; the details of each food type is given below

Cereals and pulses; teff, maize, sorghum, lentils, wheat, barley, millet, split lentils, cow peas, split cow peas, chick peas, horse beans, shiro (purchased)

Spices; berbere, salt, sugar, onion, garlic, jingible, cooking spices, and other spices

Milk and meat food items; milk/ergo, cheese, butter, beef, mutton, eggs, and fish

Vegetables and fruits; potatoes, tomatoes, carrot, gomen, keysir, karia, oranges, banana, papaya, pineapple, avocado and others

Drinks and stimulants; tella, tej, areki, soft drinks, beer, other liquor, coffee, tea, chat, cigarettes

In working's analysis, goods are necessities or luxuries and have the appropriate sign on the coefficient, that is, when $\beta_{0}<0$, the consumption declines are income rises and if $\beta_{0}>0$, the reverse is true 


\section{RESULTS AND DISCUSSION}

In this section, the researcher is going to analyze the available data by employing different data analysis methods to address the cited objectives. For the sake of understanding, the descriptive part of the analysis presented first followed by the econometrics analysis. Here it goes!

\subsection{Descriptive Analysis}

\subsubsection{Poverty issues}

Economists and development specialists agree on the perplexity of setting genuine poverty lines. For instance, the minimum calorie intake requirements for households, which are believed to play crucial roles for individual cases, in a specified period, though popularly utilized, are still flawed with debates. This is because households are composed of family members with different age and sex categories leading to differences in needs, consumption habits, and preferences. It is also true that the same level of income cannot serve equally the needs of households that are different in composition.

To minimize such problems scholars have been busy probing for a number of alternatives among which the adult equivalent scale, which establishes on equivalence in the consumption of an adult, a child, and extra, is used eminently. This study has adopted the adult equivalent consumption method in general and the cost of basic needs approaches in particular. The method of calculation for arriving this can be found in chapter two. Following this approach, this part discusses major findings of the study.

Table 3.1 Poverty Indexes of the town for the Year 2019

\begin{tabular}{|l|l|l|l|l|l|}
\hline \multirow{3}{*}{ Year } & \multicolumn{6}{|c|}{ Poverty Indexes } \\
\cline { 2 - 7 } & $\begin{array}{l}\text { Head count } \\
\text { index }\left(\mathrm{P}_{0}\right)\end{array}$ & $\begin{array}{l}\text { Total poverty } \\
\text { gap }(\mathrm{TPG})\end{array}$ & $\begin{array}{l}\text { Average poverty } \\
\text { gap }(\mathrm{APG})\end{array}$ & $\begin{array}{l}\text { Normalized } \\
\text { poverty gap }\left(\mathrm{P}_{1}\right)\end{array}$ & $\begin{array}{l}\text { Severity } \\
\text { index }\left(\mathrm{P}_{2}\right)\end{array}$ \\
\hline $\mathbf{2 0 0 0}$ & 0.45 & 992.4722 & 22.05494 & 0.25 & 0.092 \\
\hline
\end{tabular}

Source: Own survey result, 2019

As it is evident from the above table, the head count index of the city is 0.45 referring that out of the total 100 surveyed households $45 \%$ are under absolute poverty. Put differently, 45 households are unable to meet the minimum requirement of 88 birr per month per adult for the purchase of life sustaining food items. TPG in its part shows that 992 birr per month is needed (required) for making those households get out of poverty. In average terms, 22 birr per month per adult should be given as a transfer for the 45 households who are in absolute poverty to boost the purchasing power (dollar vote) of those households and thereby meet the minimum 88 birr per month per adult equivalent. The table also tells that the normalized poverty gap is 0.25 showing the size of income shortfall in relation to the poverty line.

\section{Poverty analysis for different socio-economic and demographic aspects}

To take a deep look at on the possible cause and determinant of poverty levels of different socio-economic characteristics, it needs the compilation of poverty indexes for each individual determinant that we are interested in. The findings (specifically $\mathrm{P}_{0}$ ) in the table below suggest that, the incidence of poverty is high among femaleheaded households. The reasonable argument for this situation is that, males have the highest access for income generating activities than their female counterpart in our country in general and in the city in particular. However, when we see $\mathrm{P}_{1}$ and $\mathrm{P}_{2}$, they show that even if out of the total female headed households approximately half of them are under poverty, less amount of birr per month per adult is require for those families to enable them get out of poverty than poor male-headed households.

Though it cannot be conclusive with respect to the age of the household head over the whole sample, it seems that poverty declines with age up to a certain age, specifically up to 55 years of age. Thereafter, the incidence of poverty increase with age. The decrease in poverty up to a certain age can be interpreted as the negative impact of work experience of the head (which is gained through age) on poverty.

On the other hand, poverty increases with household family size. This may reflect the importance of family planning for reducing poverty. However, care should be taken in interpreting the result because some studies argue that the hypothesis that poverty leads households to have more children is equally plausible implying that the direction of causation between poverty and family size require further investigation. 
Table 3.2 Poverty Indexes for Different Demographic Characteristics

\begin{tabular}{|l|l|l|l|l|}
\hline \multicolumn{2}{|l|}{ Determinants } & \multicolumn{2}{|c|}{ Poverty indexes } \\
\cline { 3 - 5 } \multicolumn{2}{|c|}{ Sex of the HHH } & $\mathrm{P}_{0}$ & $\mathrm{P}_{1}$ & $\mathrm{P}_{2}$ \\
\cline { 2 - 5 } & 1. male & 0.4375 & 0.2239 & 0.1645 \\
\hline \multirow{3}{*}{$\begin{array}{c}\text { Age of } \\
\text { HHH }\end{array}$} & 2.female & 0.5054 & 0.2415 & 0.1474 \\
\cline { 2 - 5 } & Up to 35 & 0.4667 & 0.2471 & 0.1632 \\
\cline { 2 - 5 } & $36-45$ & 0.4285 & 0.2388 & 0.1423 \\
\cline { 2 - 5 } & $46-55$ & 0.4371 & 0.2365 & 0.1198 \\
\cline { 2 - 5 } & $56-65$ & 0.5023 & 0.2234 & 0.1068 \\
\cline { 2 - 5 } & $>65$ & 0.5123 & 0.2547 & 0.1406 \\
\hline \multirow{3}{*}{$\begin{array}{l}\text { Household } \\
\text { family size }\end{array}$} & {$[1-3]$} & 0.4578 & 0.2243 & 0.1345 \\
\cline { 2 - 5 } & {$[4-6]$} & 0.4678 & 0.2298 & 0.1678 \\
\cline { 2 - 5 } & {$[7-9]$} & 0.5587 & 0.2034 & 0.1106 \\
\cline { 2 - 5 } & $>9$ & 0.5754 & 0.2456 & 0.1587 \\
\hline
\end{tabular}

Source: Own survey result, 2019

The findings with respect to educational level of the head reveal that poverty indexes decrease with an increase in educational attainment i.e. when we see illiterate to primary, the poverty indexes decrease, also it decrease from primary to secondary and then to college level of education. A reduction in the extent of poverty with level of education of the HHH confirms that how education is significant in fighting poverty.

The poverty profiles by the type of activity that the HHH engaged demonstrates that those households whose head are the unemployed and casual worker is the most vulnerable for poverty. The reason is basically that these households do not have regular and sufficient income (earning). In the other case, pensioners are also highly attacked by poverty while wage earners and own account workers experience the least incidence of poverty in relative terms.

Table 3. 3 Poverty indexes for different educational levels and economic activities

\begin{tabular}{|l|l|l|l|l|}
\hline \multicolumn{2}{|c|}{ Determinant } & \multicolumn{3}{c|}{ Poverty indexes } \\
\cline { 3 - 5 } Educational level of the HHH & Illiterate & $\mathrm{P}_{0}$ & $\mathrm{P}_{1}$ & $\mathrm{P}_{2}$ \\
\cline { 2 - 5 } & Primary & 0.5687 & 0.1978 & 0.1547 \\
\cline { 2 - 5 } & Secondary & 0.4756 & 0.1647 & 0.0987 \\
\cline { 2 - 5 } & College & 0.3047 & 0.2057 & 0.1745 \\
\hline \multirow{3}{*}{ Main activity of the HHH } & Unemployed & 0.1978 & 0.1489 & 0.1147 \\
\cline { 2 - 5 } & Casual worker & 0.6425 & 0.2745 & 0.1945 \\
\cline { 2 - 5 } & Pensioner & 0.6234 & 0.2945 & 0.2024 \\
\cline { 2 - 5 } & Own account worker & 0.5027 & 0.2957 & 0.1297 \\
\cline { 2 - 5 } & Wage earner & 0.4594 & 0.2345 & 0.1345 \\
\hline
\end{tabular}

\section{Source: Own survey result, 2019}

\subsubsection{Food security}

The idea of food as a human right might be as old as human history, since food and nutrition security is a primary concern in any society. In 1948, the United Nations incorporated for the first time the freedom from hunger and malnutrition into the Universal Declaration on Human Rights, Art. 25:

In addition, the "International Covenant on Economics, Social and Cultural Rights" (Art. 11) as well as the "Convention of the Rights of the Child" (Article 24) included aspects of food and nutrition security. Amongst those were adequate food, physical and mental health, medical services, disease treatment, hygiene, sanitation, sustainable environment and care.

Nevertheless, although accepted nation-wide, the right to adequate food and to be free from hunger has not yet been given sufficient attention in the context of operational development concepts.

To have a crude look at on food security, let us take meals per day of the concerned households 
Table 3.4 Meals Eaten Per Day

\begin{tabular}{|l|l|l|l|l|l|l|}
\hline \multirow{2}{*}{$\begin{array}{l}\text { Meals per } \\
\text { day }\end{array}$} & \multicolumn{3}{|c|}{ Households } & \multicolumn{2}{c|}{ Total } \\
\cline { 2 - 7 } & $\begin{array}{l}\text { In number } \\
(1)\end{array}$ & In percentage & In number (2) & In percentage & $\begin{array}{l}\text { In number } \\
(1+2)\end{array}$ & $\begin{array}{l}\text { In } \\
\text { percentage }\end{array}$ \\
\hline 1 & 7 & 20 & 6 & 9.23 & 13 & 13 \\
\hline 2 & 10 & 28.57 & 8 & 12.31 & 18 & 18 \\
\hline 3 & 14 & 40 & 40 & 61.54 & 54 & 54 \\
\hline 4 & 4 & 11.43 & 11 & 16.92 & 15 & 15 \\
\hline Total & 35 & 100 & 65 & 100 & 100 & 100 \\
\hline
\end{tabular}

Source: Own survey result, 2019

As we can observe from the above simple presentation, households, which constitute the lion's share of the total, ate 3 meals per day. On the other hand, those households taking 2 meals per day have relatively higher figure than the others. Having considered the sex of the household head, we arrive at a deduction that female-headed households take a lesser amount of meal per day than male-headed households do. However, meals per day do not suggest the achievement of food security or not, it gives some rough clue about it i.e. those households which can afford 3 or 4 meals per day for each members of the household have a higher probability of being food secured. Since $31 \%$ of the total surveyed household ate only one or two meals per day we suggest that there is a higher probability of incidence of food insecurity in the city.

The mean consumption expenditure per adult equivalent on food consumption has also been compiled for the city to highlight the average standard of living enjoyed by the dwellers of the city. And its figure is 125.6 birr per month per adult equivalent, which is well above the minimum requirement. However, it is not plausible to say that food security in the city is on better status because there is a considerable variation among households i.e. the maximum was 495.033 birr per month per adult equivalent and the minimum was 25.7 birr.

\subsubsection{Women employment}

Women have lower participation rates and face higher level of unemployment compared to their male counterparts. Empirical evidence indicates that the unemployment rate among young women (20-24) was 38.7 per cent while it was only 23.2 per cent for young men in that age category during the same year. These figures stand in contrast with the general trend for the Sub-Saharan region, where the unemployment rates for young men (23.1 per cent) exceed those for young women (18.4). The unemployment rates for the total labor force, youth and urban youth, disaggregated by gender indicates that women experience higher levels of unemployment than their male counterparts in Ethiopia. This is consistently true for all working age groups (10 years and above), for all youth (both urban and rural youth) as well as for urban youth across all reference periods.

Unemployment rates have increased more for women than for men over the five years prior to 2004. In 1999, the youth unemployment rate among women was 17.3 per cent, compared to 6.8 per cent among men. The urban female youth unemployment rate was 43.7 per cent compared to 29.4 per cent for urban male youth. This concurs with the findings from MOLSA data on registered job seekers. In 2003, female job seekers accounted for 56 per cent of the total registered job seekers. This upward trend in unemployment is, in part, a consequence of the increased participation of women in the labor force and in education.

To have a look at on the employment condition of women in the city, we should examine the main activity of adult females whose age fall under the labor forces (16-64). In our examination of women's employment, we exclude adult females at school and disables who are not on the position to undertake any economic activity.

Table 3.5 Women's Main Activity

\begin{tabular}{|l|l|l|}
\hline \multirow{2}{*}{ Type of main activity of adult females } & \multicolumn{2}{|c|}{ Respondents } \\
\cline { 2 - 3 } & In number & In percentage \\
\hline House wife & 55 & 34.48 \\
\hline Domestic worker & 17 & 10.96 \\
\hline Casual worker & 3 & 1.93 \\
\hline Unemployed & 19 & 12.25 \\
\hline Pensioner & 8 & 5.16 \\
\hline Household female business & 15 & 9.67 \\
\hline Own account worker & 6 & 3.87 \\
\hline Wage earner & 38 & 20.64 \\
\hline Total & 155 & 100 \\
\hline
\end{tabular}

Source: Own survey result, 2019

From the above table we observe that most of adult females engaged in non-economic activities i.e. $34.48 \%$ of the total adult females are house wife implying that they do not have their own income generating source. In other words, they are merely dependent on their husbands' income which makes them subordinate and ineffective 
in passing decisions concerning the household. The number of female unemployed out of the total adult females is also higher with respect to the other non-economic activities. Surprisingly, only $20.64 \%$ of adult female are wage earner and $3.87 \%$ has run their own formal business. In general, almost $78 \%$ of adult female are engaged in non-economic activity in the city.

\subsection{Econometrics Analysis}

\subsubsection{Determinants of poverty}

The descriptive analysis in the previous section has already clearly identified some determinants of the probability of being under poverty. However, to investigate this more carefully calls for a multivariate analysis, considering many factors together. This is considered here by estimating the factors influencing the likelihood of a household being under poverty, by means of a logit model. The explanatory variables used in this model are summarized in chapter three; these include characteristics such as household demographics; main economic activity of the head; education of the head; gender, and residence before ten years. As before, these are the values of these variables in the survey year (2019). While many of these were considered individually in the previous section, the regression model enables the simultaneous effects of these different factors to be considered and so gives a more robust assessment of their importance. For the estimation of the model, stata-9 application software was used.

Before analyzing determinants of urban poverty, all variables, which were hypothesized to depict incidence of poverty in the study area, were checked for multicollinearity using pair-wise correlation coefficient. The result of the test confirmed that there is a moderate collinearity between college education and wage employment $(0.47)$ whereas the rest of the variables did not show significant collinearity. Wage employment and college education are, therefore, taken as detrimental variables for their collinearity is less than 0.7 .

Besides, the overall fitness of the model is found to be very good because the calculated value of LR chi' is much greater than its tabulated value. In other words, its p-value is 0 .

Basing the estimates and the above tests, now we are going to interpret and analyze the significance of each explanatory variable in determining the probability of being poor. In addition, the type of relationship that exists between the explanatory variables and dependent variable was analyzed.

Table 3.6 Logit maximum likelihood estimates

\begin{tabular}{|l|r|r|l|}
\hline Explanatory variables & Coefficient & $\mathbf{Z}$ & $\mathbf{P}>|\mathbf{Z}|$ \\
\hline sex of hhh & 2.4826 & 1.99 & $0.043^{* *}$ \\
\hline primary & -0.1132247 & -0.12 & 0.907 \\
\hline secondary & -3.652882 & -1.97 & $0.049^{* *}$ \\
\hline college & -3.117586 & -2.02 & $0.034^{* *}$ \\
\hline age of hhh & -0.1563392 & -2.9 & $0.004^{* *}$ \\
\hline age square & 0.0005966 & 1.35 & 0.178 \\
\hline marital status & -3.499883 & -3.07 & $0.002^{* * *}$ \\
\hline wage earner & -3.665469 & -1.78 & $0.097^{*}$ \\
\hline own account worker & -3.42582 & -1.58 & $0.139^{\#}$ \\
\hline pensioner & 0.6524294 & 0.22 & 0.827 \\
\hline casual worker & 0.0387654 & 0.01 & 0.989 \\
\hline unemployed & 0.1909243 & 0.06 & 0.95 \\
\hline family size & 0.9636165 & 2.91 & $0.004 * * *$ \\
\hline residence before 10 year & 0.3028024 & 0.26 & 0.798 \\
\hline
\end{tabular}

Source: Own survey result, 2019

$* * *, * *, *{ }^{\#}$ significant at $1,5,10$ and 15 percent level respectively

As we can clearly saw from Table 3.6 gender of the household head has a positive and significant relationship with the probability of the household to be poor i.e. those households whose head are female are highly affected by poverty than male-headed households. The possible and reasonable argument for this situation could be maleheaded households had good opportunities for employment and investment, and had wider probability to escape from the prevail poverty than females-headed households.

The econometrics results from the logit model suggest that, the probability of being poor has a significant and negative correlation with age. Meaning, the higher the age of the household head the lesser probability that the household being under poverty. This may be explained by the benefit in terms of the increase in earning power associated with work experience of the head as his age increases. However, from the positive age square result we can draw an inference that the probability of being poor is higher at very low and very high age levels.

As far as the marital status of the household head and the probability of being under poverty are concerned, a negative and significant relationship does exist between them. This is to mean that the probability of being poor for households' whose head is at marriage is less than those households headed by persons without marriage (divorced, widowed and single). This can be elucidated by the argument that those households at marriage have 
the chance of two different income sources.

The econometric results also reveal that, household family size has a positive and significant effect on the probability of being poor. This attests that households with large number of family size are more likely to be poorer than households with small (few) members. This may suggest that the disadvantage from free riding in consumption by some household members is by far larger than the benefit that the household obtains as a result of returns to scale in consumption as household size increase in the city.

On the other hand, the impact of educational level of the household head is found to be a significant one. This is to mean that all the dummies for completion of primary, secondary and college are negative associated with probability that the household is poor though their significance is not same i.e. secondary and college educational levels are found to be significant while primary is not. This discloses that those households with formally educated heads are less likely to be under poverty than those with no formal education. In other words, the probability of being poor increases as the household does not have formal education. This is not surprising since it is consistent with human capital theory where education is assumed to be increase production and hence earnings. This is also intuitively appearing especially in the urban areas where formal education is taken as a requirement in getting a job at least for skilled laborers. On the top of the significance, one point that should be get stress is that the coefficients of the schooling dummies are not the same for the different levels of education. This may suggests that different levels of education affect poverty in different amount compared to those no formal education at all.

Looking on the econometrics results, we can also identify the relationship that exists between type of economic activity of the household head and the probability of being poor. As we have seen from the table, wage earners and owns account workers are less likely to be exposed to poverty while those families whose head are casual worker, unemployed, and pensioner are in risk of poverty.

Finally, residence before ten years has a positive but insignificant relationship with the probability being under poverty i.e. those households which lived more than ten years in the city have relatively low probability being under poverty.

\section{Marginal effect of the explanatory variables on the probability of being poor}

Table 8 in the annex displayed the marginal effect of each individual explanatory variable on the probability of being under poverty. From this table we understand that the marginal effects of sex, marriage and college are found to be much higher. And the marginal effects of secondary, wage, and own account worker also appeared significant. 3.2.2 The effect of percentage share of female's income in a family on the expenditure of different food items

Based on the already specified Engel curve model in chapter three, the respective expenditures on each food items was regressed on per capita income, household family size, educational attainment of the household head, and natural logarithm of the percentage share of females income in a household and we get the following results.

Table 3.7 the effect of percentage share of female's income in a household on food expenditure

\begin{tabular}{|c|c|c|c|c|c|}
\hline \multirow{2}{*}{$\begin{array}{l}\text { Explanatory } \\
\text { variables }\end{array}$} & \multicolumn{5}{|c|}{ Dependent variable: Expenditure on different food items } \\
\hline & $\begin{array}{ll}\text { Cereals } & \text { and } \\
\text { pulses }\end{array}$ & Spices & Milk and meat & $\begin{array}{l}\text { Vegetables } \\
\text { and fruits }\end{array}$ & $\begin{array}{l}\begin{array}{l}\text { Drinks and } \\
\text { stimulants }\end{array} \\
\end{array}$ \\
\hline $\begin{array}{l}\text { Female income } \\
\text { share }\end{array}$ & $\begin{array}{l}1.525 \\
(1.763) \\
\end{array}$ & $\begin{array}{l}0.201 \\
(1.988)^{*}\end{array}$ & $\begin{array}{l}0.596 \\
(1.370)\end{array}$ & $\begin{array}{l}0.315 \\
(2.192)^{* *}\end{array}$ & $\begin{array}{l}-0.108 \\
(0.922)\end{array}$ \\
\hline $\begin{array}{ll}\text { Per } & \text { capita } \\
\text { income } & \\
\end{array}$ & $\begin{array}{l}1.360 \\
(8.904) * * *\end{array}$ & $\begin{array}{l}0.418 \\
(7.399) * * *\end{array}$ & $\begin{array}{l}0.293 \\
(3.857)^{* * * *}\end{array}$ & $\begin{array}{l}0.168 \\
(4.464) * * *\end{array}$ & $\begin{array}{l}0.115 \\
(3.548)^{* * * *}\end{array}$ \\
\hline Family size & $\begin{array}{l}35.923 \\
(7.976)^{* * *}\end{array}$ & $\begin{array}{l}10.496 \\
(6.299)^{* * *}\end{array}$ & $\begin{array}{l}9.747 \\
(4.352)^{* *}\end{array}$ & $\begin{array}{l}3.551 \\
(3.195)^{* * *}\end{array}$ & $\begin{array}{l}2.201 \\
(2.299) * *\end{array}$ \\
\hline $\begin{array}{l}\text { Educational } \\
\text { level of HHH }\end{array}$ & $-4.603(-0.386)$ & $\begin{array}{l}11.857 \\
(2.685)^{* * *}\end{array}$ & $5.97(1.006)$ & $\begin{array}{l}7.688 \\
(2.610)^{* *}\end{array}$ & $\begin{array}{l}4.081 \\
(1.609) \\
\end{array}$ \\
\hline R-SQUARE & 0.649 & 0.549 & 0.358 & 0.374 & 0.214 \\
\hline
\end{tabular}

Source: Own survey result, 2019

Note: the numbers in the bracket are the $\mathbf{t}$-values of each parameter.

: ***,**, *, Significant at 1,5 and 10 percent level respectively

As we can observe from the above Engel curve regression results, both income per capita and family size have a positive and significant relationship with expenditure on cereals and pulses at $1 \%$ significance level. This is to mean that as income per capita or family size increases, the expenditure on cereals and pulses will increase as well, keeping the other explanatory variables unchanged. On the other hand, the effect of percentage share of female's income in a household is positive but statistically insignificant at $5 \%$ significance level. On the other extreme, the effect of education in this particular food item expenditure is negative and insignificant. The implication is that as the household head completed higher and higher education, his expenditure on cereals and pulses decrease, citrus paribus, though by an insignificant amount.

Having diverted our concern from cereals and pulses to spices, we get similar but slightly different results 
from the former finding. The similarity is that both per capita income and family size retain their positive and significant effect here also. However, the difference arises from the relationship that exists between education and expenditure on spices i.e. the Engel curve regression result suggests that there is a positive and significant relationship between education and expenditure on spices. When we take a look at on the effect of percentage share of female's income in a family on the expenditure of spices, we can say that it has a similar effect as that of expenditure on cereals and pulses. Even if this deduction is right, however, the effect of this explanatory variable on the two expenditures differs on the ground of its significance. Meaning at significance level of $5 \%$ the effect on both expenditures is not worthwhile. However, if we take $10 \%$ significance level the result will be different i.e. the extent of the effect of percentage share of female's income in a family is appeared to be greater on spices expenditure.

As far as the effects of income per capita and family size on the expenditure of milk and meat food items are concerned, the Engel curve regression result confirms that the two explanatory variables still keep their positive and significant effect. Whereas both education and percentage share of female's income in a family has a positive but insignificant effect on the expenditure of milk and meat at both 5 and 10 percent significance level. Since our business here is to examine the effect of percentage share of female's income in a family on different types of food expenditures, we have to compare the degree (significance) of its effect on each food item. By doing so, we can say that the effectiveness of percentage share of female's income in a family in influencing the expenditure pattern of households on milk and meat is found to be lesser than the above two.

As it is evident from the Engel curve regression result, income per capita and family size are found to be positively as well as significantly related with expenditure on vegetable and fruits once again. Moreover, education is also has a positive and significant effect on household's expenditure on vegetables and fruits at $5 \%$ significance level. In other words, as the level of education of the households head increases the expenditure on vegetables and fruits increases, citrus paribus. The regression result also attested that the percentage share of female's income in a family has a positive and significant effect on vegetables and fruits expenditure at 5\% significance level. This could be interpreted as the more the share of females' income in the family, the higher expenditure on vegetables and fruits will be.

Finally, observing the Engel curve regression results once again bears out that, income per capita and family size till keep hold of their positive and significant effect on the expenditure on drinks and stimulants. What is strange here is that, the impact of percentage share of female's income in a family has a negative but insignificant effect on the expenditure of drinks and stimulants. The result also told us that educational level and expenditure on drinks and stimulants are positively related.

In conclusion, from the overall findings of this sub section we perceive that percentage share of female's income in a family has a positive and significant effect on the expenditure of spices, and vegetables and fruits. In addition, it is found that there is a positive but insignificant relationship between percentage shares of female's income in a family and expenditure on cereals and pulses, and milk and meat food items while its effect on drinks stimulants is negative and insignificant.

What is the implication of the results? The implication of the results is that if female's income shares in a family increases, it is possible to achieve not only food security but also nutrition security. For this to happen, it is obligatory to empower women in socio-economic and political affairs.

\section{CONCLUSIONS AND RECOMMENDATIONS \\ 4.1 Conclusion}

The objectives of the study were: to assess determinants and their quantitative relationships up on urban poverty, to examine the effect of percentage share of female's income in a family on food expenditure, and the condition of women employment in Sodo town. A total of 100 households were selected from the inhabitants of the town during the 2019.

The research used the cost of basic needs approach in the identification of the poor from the non-poor. Based on this approach out of the 100 surveyed households $45(45 \%)$ of them were found below the poverty line. That incidence of poverty is rampant and hardcore among the surveyed: 0.45 the head count, 0.25 normalized poverty gap, and 0.092 as the severity index in the town respectively calls for urgent interventions aimed at curbing the fate of the poor. One way of doing this is through identifying factors that account for urban poverty. This, however, requires analytical rigor, as the factors are complicated and important as well in fighting against poverty. Although a number of specific conclusions could be drawn from the estimation results, summaries and sum ups of this research, among other things, include the following: The study found out that female-headed households are more likely to be poorer than households of which the head is men. Household size was positively and significantly correlated with poverty in Sodo town as the study depicted. This has a clear implication for the residents of the city in that households with large size will fall into the hardcore sections of poverty easily than those who have not. Educational status of the head was appeared a significant factor in determining the probability of being poor. Meaning, those households whose head has attended more schooling is less likely to be in absolute poverty. Age 
of the household head also has a negative and significant effect on the probability of being poor. This is to mean that as age of the hhh increases the probability of being under poverty go down. However, this did not hold for all age levels because as we can observe from the age square result, the very high age of the hhh is, the higher the probability of the household being under poverty. The economic activity of the hhh also has found a significant effect on the status of poverty of a household i.e. households whose head are wage earner and own account worker have less probability of being under poverty. Most of the surveyed households i.e. $54 \%$ could afford three meals per day for their members. On the contrary, a significant amount of households were unable to eat three meals per day. As to the employment of women the study found that $78 \%$ of adult females were engaged in non-economic and less paid jobs and activities. Finally but most importantly, the study found that the percentage share of female's income in a household has a positive and significant effect on expenditures of a household on vegetables and fruits, and spices.

\subsection{Recommendations}

Based on the findings reached up on, the study come up with the following recommendations

* As it was evident from the head count poverty index, nearly half of the surveyed households were under poverty i.e. they were unable to meet the minimum expenditure on food items for survival. From this result, therefore, the study suggests that urban poverty should be get due emphasis from the concerned body.

* The findings revealed that most female-headed households were under poverty than their male counterparts. In addition, the lion share of adult females was engaged in non-economic and less remunerative jobs and activities. Thus, it entails that both intensive and extensive projects and programs must be done to empower women in socio-economic and political affairs.

* As the educational attainment of the head of the household is found to be the most important factor associated with urban poverty, it clearly suggests ways of focusing on the value of education. Adequate education is central in addressing incidence of poverty. Specifically, college education is found to be of paramount importance in reducing poverty in Sodo town

* Creating a good employment opportunities for women has a paramount of significance not only in the alleviation of poverty and achievement of food security but also for realization of nutrition security

* Since most of the households which are headed by old age persons are under absolute poverty, there should be a good social security system as far as what is possible.

\section{Bibliography}

Abbi M.Kedir and Andrew McKay (2003), Chronic Poverty in Urban Ethiopia: Panel Data Evidence, Paper prepared for International Conference on 'Staying Poor: Chronic Poverty and Development Policy', hosted by Institute for Development Policy and Management, University of Manchester, UK, 7 - 9 April 2003

Abebe Shimeles and Arne Bigsten (2008), The persistence of urban poverty in Ethiopia: A tale of two measurements, Working Papers in Economics No 283, Goteborg University

Asmamaw Enquobahrie (2004), Understanding Poverty: The Ethiopian Context, A Paper presented at The Gambia AAPAM Roundtable Conference, Banjul, The Gambia, April 19 - 23, 2004

Constantina Safiliou-Rothschild (2001), Food Security and Poverty: Definitions and Measurement Issues, Dialogue Working Paper 4

Dejene Aredo (2005), Migrant Remittances, Shocks and Poverty in Urban Ethiopia: an Analysis of Micro Level Panel Data, Addis Ababa University

Elisa Muzzini (2008), Urban Poverty in Ethiopia: A Multi-faceted and Spatial Perspective, The World Bank Group, Washington D.C.

Esubalew Alehegn (2006), Determinants of Urban Poverty: The Case of Debre Markos, MA Thesis in Regional and Local Development Studies

G.S. Maddala (1992), Introduction to Econometrics, second edition, Macmillan publishing company, New York

Gujarati, Damodar N. (2004), Basic Econometrics, $4^{\text {th }}$ edition, Tata McGraw-Hill Company, New York

Ines Reinhard and K.B.S Wijiyaratne (2000), The use of Stunting and Wasting as indicators of Food Insecurity and Poverty, Working Paper 27

John Simister and Jenifer Piesse (2002), Household Consumption Decisions and Nutrition in South Africa, Centre for the Study of African Economies Conference,St Catherine.s College, Oxford

Martin Ravallion (2005), Evaluating Anti-Poverty Programs, Development Research Group, World Bank

MEDAC and UNCHS (Habitat) (2000), An Overview of Urban Poverty in Addis Ababa, Addis Ababa.

Michael P. Todaro and Stephen C. Smith (2003), Economic Development, $8^{\text {th }}$ edition, Dorling Kindersley Pvt. Ltd, India

Milu Muyanga (2006), Household Vulnerability to Transient and Chronic Poverty: Evidence from Rural Kenya, Egerton University (Kenya) 
Quisumbing, Agnes R. and Bonnie McClafferty (2006), Using Gender Research in Development, International Food Policy Research Institute

Raj Nallari (2004), Poverty Measurement, World Bank Institute

Sarah Gammage (2006), A Menu of Options for Intra-Household Poverty Assessment, United States Agency for International Development

Tesfaye Alemayehu Gebremedhin (2006), The Analysis of Urban Poverty in Ethiopia, The University of Sydney Woodldridge, Jeffrey M., Introductory Econometrics, A Modern Approach, second edition

\section{Annex}

Table 8 Marginal effects of the explanatory variables on the probability of being poor

\begin{tabular}{|c|c|c|c|c|c|c|}
\hline \multicolumn{3}{|c|}{ Marginal effects after logit } & & & & \\
\hline \multicolumn{3}{|c|}{$\mathrm{y}=\operatorname{Pr}($ povstatus $)$ (predict) } & & & & \\
\hline \multicolumn{7}{|c|}{$=.29785064$} \\
\hline Variable & $\mathrm{dy} / \mathrm{dx}$ & Std. Err. & $\mathrm{z}$ & $\mathrm{P}>\mathrm{Z}$ & \multicolumn{2}{|l|}{$[95 \%$ C.I. $]$} \\
\hline sexhhh* & .5072762 & .23345 & 2.17 & 0.030 & .049713 & .964839 \\
\hline primary* & -.0235608 & .19964 & -0.12 & 0.906 & -.414843 & .367722 \\
\hline second $\sim y^{*}$ & -.4810376 & .12132 & -3.97 & 0.000 & -.718818 & -.243257 \\
\hline college* & -.6444211 & .22401 & -2.88 & 0.004 & -.805361 & .48348 \\
\hline age & -.0326961 & .01309 & -2.50 & 0.013 & -.058355 & -.007038 \\
\hline agesqu $\sim \mathrm{e}$ & .0001248 & .0001 & 1.23 & 0.217 & -.000073 & .000323 \\
\hline marita $\sim \mathrm{s}^{*}$ & -.6105133 & .14135 & -4.32 & 0.000 & -.887551 & -.333475 \\
\hline wage* & -.5230431 & .30152 & -1.73 & 0.083 & -1.11401 & .067924 \\
\hline ownacc $\sim r^{*}$ & -.4395887 & .24553 & -1.79 & 0.073 & -.920826 & .041649 \\
\hline pensio $\sim r^{*}$ & .1461117 & .69775 & 0.21 & 0.834 & -1.22146 & 1.51368 \\
\hline casual* & -.00806 & .58715 & -0.01 & 0.989 & -1.15886 & 1.14274 \\
\hline unempl $\sim \mathrm{d}^{*}$ & .0409318 & .6698 & 0.06 & 0.951 & -1.27185 & 1.35372 \\
\hline family $\sim \mathrm{e}$ & .2015265 & .06444 & 3.13 & 0.002 & .075224 & .327829 \\
\hline reside $\sim s^{*}$ & .0659258 & .2678 & 0.25 & 0.806 & -.458953 & .590805 \\
\hline \multicolumn{3}{|c|}{$(*) \mathrm{dy} / \mathrm{dx}$ is for discrete change of } & dummy & variable & from 0 to 1 & \\
\hline
\end{tabular}

